\title{
Universidade e sociedade: diálogos silenciados
}

\author{
Maria Ivete Basniak, Antônio Charles Santiago \\ Almeida \& Sani de Carvalho Rutz da Silva
}

\begin{abstract}
Infelizmente, temos verificado que há um fosso entre o lugar de produção científica, as universidades e a comunidade. Decerto que existe, por parte de alguns pesquisadores, um esforço no sentido de aproximar a produção científica das comunidades, mas, no seu conjunto, pode se afirmar que este é um diálogo interrompido. Neste trabalho, objetivamos discutir possibilidades e desafios da extensão universitária ser um meio para aproximar o conhecimento produzido na universidade da sociedade, para que seja relevante socialmente, acessível e pronto para ser utilizado. Assim, partimos da hipótese de que há um distanciamento entre as pesquisas produzidas e a extensão praticada nas universidades brasileiras. Verificamos isso comparando a produção acadêmica de professores que possuem programas e projetos de extensão, cadastrados na divisão de extensão de uma universidade pública brasileira. A análise dos objetivos desses projetos junto a experiência do projeto do Laboratório Gilberto Freyre, nos permitem também tecermos uma crítica à forma como a extensão universitária é realizada, ou seja, a universidade produz a extensão sem uma escuta às comunidades. Todavia, não se pode objetar a impossibilidade de fazer com que ciência e sociedade possam, de forma fluída, dialogar e produzir saber.
\end{abstract}

Palavras-chave:

universidade; sociedade; extensão; ciência. 


\section{University and society: silenced dialogues}

Abstract: Unfortunately, we have checked that the reis a gap between scientific production place, universities, and community. Certainly some researchers have made an effort to bring the scientific production closer to the communities, but, as whole, it can be said that this is an interrupted dialogue. In this research, we aim to discuss the possibilities and challenges of university extension as a means to bring knowledge produced in the university of society so that it is socially relevant, accessible and ready to be used. Thus, we have started from the hypothesis that there is a gap between the researches produced and the extension practiced in the brazilian universities. We have checked this, comparing the academic production of professors Who have extension programs and projects, registered in the extension division of a brazilian public university. The analysis of the objectives of these projects together with the experience of the Gilberto Freyre Laboratory project, also allow us to critique the way university extension is carried out, that is, the university produces extension without listening to the communities. However, it can't object to the impossibility of making science and society as a flowing way to dialogue and produce knowledge.

Keywords: university; society; extension; science.

\section{Université et société: dialogues silencieux}

Résumé: Malheureusement, nous avons constaté qu'il y a un écart entre le lieu de la recherche scientifique, des universités et de la communauté. Certes, il est, par certains chercheurs, un effort pour se rapprocher de la production scientifique des communautés, mais dans son ensemble, on peut dire que ceci est un dialogue interrompu. Dans cette recherche, nous cherchons à discuter des possibilités et des défis de l'extension de l'université en tant que moyen d'apporter les connaissances générées à l'Université de la société à être socialement pertinente, accessible et prête à l'emploi. Donc, nous partons de l'hypothèse selon laquelle il existe un écart entre la recherche produite et l'étendu et pratiquée dans les universités brésiliennes. Nous avons vérifié cela en comparant la production académique des enseignants qui ont des programmes et des projets d'extension, en registres dans la division de l'extension d'une université publique brésilienne. L'analyse des objectifs de ces projets avec l'expérience du projet de laboratoire Gilberto Freyre, nous permet aussi critiquer la façon dont l'extension de l'université est réalisée, cela veut dire que l'université produit l'extension sans écouter les communautés. Toutefois, on ne peut pas opposer à l'impossibilité de faire que la science et la société puisse, de forme fluide, dialoguer et produire du savoir.

Mots-clés: université; société; extension; science.

\section{Universidad y sociedad: diálogos silenciados}

Resumen: Por desgracia, es sabido que hay una grande distancia entre las universidades, que ocupan un lugar de institución científica, y las comunidades en su entorno. Ciertamente hay, por algunos investigadores, un esfuerzo para aproximar la producción científica de las comunidades, pero en su conjunto se puede decir que se trata de un diálogo interrumpido. En este trabajo, nuestro objetivo es analizar las posibilidades y desafíos de la extensión universitaria, para que esta sea un medio para llevar el conocimiento generado en la universidad a la sociedad, para que este mismo conocimiento sea socialmente relevante, accesible y utilizable Así que partimos de la hipótesis de que hay una distancia entre la investigación producida y la extensión practicada en las universidades brasileñas. Se verificó mediante la comparación de la producción académica de los profesores que tienen programas y proyectos de extensión, registradas en la división de extensión de una universidad pública brasileña. El análisis de los objetivos de estos proyectos con la experiencia del proyecto Laboratorio de Gilberto Freyre, nos permite también hacer una crítica de cómo se realiza la extensión universitaria en Brasil, o sea, de cómo la universidad produce la extensión sin escuchar a las comunidades. Sin embargo, no puede oponerse a la imposibilidad de hacer que la ciencia y la sociedad puede, en forma fluida, el diálogo y la producción de conocimiento.

Palabras clave: universidad; empresa; extensión; ciencia. 


\section{Introdução}

Pretendemos discutir neste trabalho possibilidades e desafios da extensão universitária ser um meio para aproximar o conhecimento produzido na universidade da sociedade, para que seja relevante socialmente, acessível e pronto para ser utilizado. Nessa perspectiva a produção do conhecimento ultrapassa a barreira que há entre a produção e uso que se faz do conhecimento que de acordo com Naidorf e Perrotta, (2015, p. 22): “[...] implica ir más allá de la tradicional etapa de difusión: sería una función adicional del investigador en ciências sociales encontrar caminos que enlacen la producción del conocimiento social con la utilización de ese mismo conocimiento social producido".

Para isso, tomamos como elementos de análise sessenta e três projetos e programas cadastrados na divisão de pesquisa de uma universidade pública do Brasil correspondente a trinta e três proponentes, tendo em vista que sete proponentes possuem mais que um programa ou projeto cadastrado. De posse desses dados realizamos busca no currículo lattes dos proponentes verificando se o programa ou projeto está registrado em seu lattes, a titulação do proponente e se ocorreu difusão de resultados desses projetos por meio de publicações, artigos em periódicos, livros ou capítulos de livros e artigos completos ou resumos publicados em eventos nacionais, internacionais, locais ou regionais.

Observamos também o objetivo do projeto ou programa a fim de identificar se ação extensionista propunha a escuta a comunidade ou apenas difusão do conhecimento acadêmico contrastando com dados coletados das experiências iniciais junto ao Laboratório Gilberto Freyre. Este laboratório de pesquisa/extensão, cadastrado na Pró-reitoria de extensão da Universidade Estadual do Paraná, dispõe de um grupo de pesquisadores, composto por docentes e discentes da universidade que atuam na comunidade de União da Vitória, Paraná. As atividades de extensão que são desenvolvidas partem de um diálogo entre universidade e comunidade, ou seja, os projetos são elaborados em conversa conjunta para que os acadêmicos, participantes do laboratório, aprendam que a extensão universitária não pode ser pensada vertical e hierarquicamente, mas, para, além disso, como via de mão dupla, quer dizer, universidade/ comunidade e comunidade/universidade. Nesse sentido, o laboratório Gilberto Freyre, tem se configurado como elemento de escuta das comunidades, onde docente e discente sentam com as comunidades para ouvir seus cotidianos e, a partir disso, em conjunto, formalizarem projetos. O papel dos pesquisadores é, no primeiro momento de escuta e, no segundo momento, formalização e execução de atividades que foram suscitadas no conjunto dos diálogos. E para realização dessas atividades, projetos construídos com a comunidade, o laboratório formaliza parcerias com entidades públicas e privadas. No momento, existem dois alunos bolsistas que recebem da prefeitura 
de União da Vitória para desenvolver atividades de capoeira, contação de história com adolescentes e jovens em condições de vulnerabilidade social, também adolescentes e jovens que cumprem medidas socioeducativas e crianças e adolescentes com medidas protetivas.

\section{A universidade e a produção de conhecimento}

a universidade é uma das, senão a principal responsável pela produção científica, pois é no meio acadêmico que se concentram a maioria dos pesquisadores responsáveis por investigações que impulsionam novas pesquisas, criando assim um círculo de busca do saber.De acordo com Perini e Bufrem (2008, p. 27) ainda que a "pesquisa na universidade seja propulsora de soberania, algumas questões afloram diante das críticas que vêm sendo feitas à formação dos pesquisadores na universidade".

Pois, como critica Milton Santos em entrevista à revista Caros Amigos: "A universidade pública seria o lugar do intelectual público. Mas hoje a possibilidade de ser intelectual público é cada vez mais limitada [...]" (Santos, 2016, s.d.).

Santos (2016) denuncia a submissão do conhecimento produzido na universidade ser subserviente aos interesses do mercado e a globalização:

Não basta pensar, tem de poder dizer. Por conseguinte, se o ensino ficar atrelado ao mercado ou à técnica, ele será cada vez mais canalizado para a subserviência, sobretudo porque a ciência tende cada dia a ficar mais longe da verdade. Porque a ciência é feita para responder à demanda da técnica e do mercado. Por conseguinte ela estreita seu objetivo. Só o ensino público pode restaurar isso (Santos, 2016, s.d.).

Assim, embora a universidade tenha passado por reformas, que não discutiremos nesse trabalho, uma vez que não é nosso objetivo, mas que o leitor interessado pode obter mais detalhes em Vieira Pinto (1994) e Perini e Bufrem (2008), ainda hoje verificamos a necessidade de mudanças, pois:

As universidades criam inércias como quaisquer outras instituições e, para, além disso, são dotadas de um valor social - ligado à produção de conhecimento - que facilmente sobrepuja o valor real (em termos de produção e de produtividade) do conhecimento efetivamente produzido por alguns dos universitários (Santos, 2016, p. 141).

Embora as pesquisas realizadas hoje em sua maioria estejam disponíveis à sociedade em geral graças ao acesso livre e virtual, a população em geral não faz uso desse 
conhecimento, ao menos não de forma direta. Talvez seja pela linguagem usada que parece carregar propositalmente um formalismo e densidade em sua escrita que não condiz com os textos que são lidos no meio não acadêmico. E nesse sentido incluímos as instituições de ensino públicas e privadas, ou seja, as escolas de Educação Básica, em que o conhecimento científico necessita ser reescrito em livros didáticos ou apostilas para ser trabalhado com as crianças e jovens, o que a nosso ver, reitera o quanto a produção científica se faz distante da sociedade, ainda que em espaços formais de educação.

São duras as críticas que presenciamos atualmente relacionadas ao controle que a mídia exerce sobre a população, talvez isso se deva a essa ruptura que há entre o conhecimento produzido no meio acadêmico e o conhecimento que a população em geral acessa, o qual na maioria das vezes ocorre por veículos midiáticos, em que a televisão ou as revistas não científicas apresentam à população os acontecimentos atuais, baseados em uma análise do senso comum, em opiniões e observações sem base científica, ou ainda, em releituras, muitas vezes equivocadas de pesquisas científicas. Assim, a população fica a mercê da mídia para compreender a realidade e também para tomar decisões.

Desse modo, quando nos perguntamos a quem esse conhecimento serve, observamos uma ruptura entre o conhecimento produzido nas universidades e o conhecimento que veicula junto à sociedade.

Embora isso seja muito criticado no meio acadêmico, essas censuras em geral consideram que a população, embora tenha acesso ao conhecimento científico opta pela ignorância escolhendo essa via. Não há a nosso ver, um esforço na academia para tornar o conhecimento acadêmico realmente acessível à população em geral. Vieira Pinto (1994, p. 19) declarou que:

a universidade é uma peça do dispositivo geral de domínio pelo qual a classe dominante exerce o controle social, particularmente no terreno ideológico, sobre a totalidade do país. Se tal é a essência da universidade, deste logo se vê que o problema de sua reforma é político e não pedagógico. Este último aspecto existe, é claro, mas se mostra secundário, pois só se apresentará na forma em que pode e deve ser resolvido, depois que tiver sido decidido politicamente o destino da universidade e sua participação no projeto de transformação social empreendido pela comunidade.

Impulsionada por diferentes vertentes motivos políticos, econômicos e estruturais, a indissociabilidade entre ensino, pesquisa e extensão consolidou-se na Lei de Diretrizes e Bases, Lei 9394/1996, embora como cita Perini e Brufrem (2008) até hoje na prática a comunidade acadêmica tenha dificuldades em compreender, esse tripé. 
Acreditamos que a principal dificuldade se centra na compreensão da extensão universitária, claramente conceituada no I Fórum Nacional de Pró-Reitores de Extensão:

\begin{abstract}
A Extensão Universitária é o processo educativo, cultural e científico que articula o Ensino e a Pesquisa de forma indissociável e viabiliza a relação transformadora entre Universidade e Sociedade. A extensão é uma via de mão-dupla, com trânsito assegurado à comunidade acadêmica, que encontrará, na sociedade, a oportunidade de elaboração de práxis de um conhecimento acadêmico. No retorno à Universidade, docentes e discentes trarão um aprendizado que, submetido à reflexão teórica, será acrescido àquele conhecimento. Esse fluxo, que estabelece a troca de saberes sistematizados, acadêmico e popular, terá como consequência a produção do conhecimento resultante do confronto com a realidade brasileira e regional, a democratização do conhecimento acadêmico e a participação efetiva da comunidade na atuação da Universidade. Além de instrumentalizadora deste processo dialético de teoria/prática, a Extensão é um trabalho interdisciplinar que favorece a visão integrada do social (Forum..., 2000/2001, apudPerini e Brufrem, 2008, p.30).
\end{abstract}

Em geral, essa via de mão-dupla não é presenciada, sendo que a tendência que se observa ainda é da extensão como curso, como complemento, como prestação de serviços ou como "remédio". (Perini e Brufrem, 2008).

Portanto, a indissociabilidade entre ensino, pesquisa e extensão carece ser discutida dentro da universidade, para que tenhamos pesquisas que retratem e discutam as necessidades da sociedade pautadas em sua realidade.

\title{
A extensão como via de mão única e a dissociabilidade entre a extensão e a pesquisa
}

Após analisarmos o objetivo de sessenta e três projetos ou programas cadastrados na divisão de pesquisa de uma universidade pública brasileira a fim de identificar se ação extensionista propunha a escuta a comunidade ou apenas difusão do conhecimento acadêmico, verificamos que trinta e quatro diferentes verbos foram usados para descrever a ação proposta pelo programa ou projeto: ampliar, aplicar, apresentar, aprimorar, atrair, capacitar, compartilhar, conscientizar, contribuir, desenvolver, diagnosticar, diminuir, disseminar, ensinar, estimular, estruturar, fornecer, implementar, incentivar, instrumentalizar, mensurar, oferecer, ofertar, permitir, projetar, promover, proporcionar, realizar, rediscutir, sensibilizar, simular, transmitir, utilizar, validar. Destes, 
cerca decinquenta por cento, pela sua própria definição já sugerem ação impositiva, ampliar, aplicar, apresentar, atrair, capacitar, desenvolver, disseminar, estruturar, fornecer, implementar, instrumentalizar, mensurar, ofertar, simular, transmitir, utilizar, validar, excluem a participação dos sujeitos que serão alvos da ação extensionista, de participação na definição e/ou redefinição das ações. Porém, ao analisar o contexto em que a ação é proposta, identificamos que apenas quatro dos sessenta e três projetos e programas cadastrados possuem indícios em seu objetivo de possibilidade de ouvir a comunidade a que se refere. Pois, as ações estão centradas no sujeito da universidade e coloca aqueles com quem a proposta se desenvolverá como alvo e não sujeitos, visto que ao citar: "Proporcionar a docentes, discentes e público em geral conhecimento de temas científicos atuais" se refere à universidade prestando esse auxílio diretamente com um plano já estruturado, sabendo que esse é o melhor caminho ainda que não tenha realizado escuta a comunidade, entendendo assim, que a universidade é a detentora do conhecimento e sabe o que a comunidade precisa.

De acordo com Marx, nas teses contra Feuerbach, a filosofia deve superar o caráter interpretativo e assumir caráter de transformação. Decerto que esta assertiva deve ser pensada dentro de um contexto específico, a saber, a esquerda hegeliana. Nesse contexto, não se trata de afronto aos filósofos, mas, antes disso, ao modelo de produção de saber orquestrado pelos pensadores vinculados ao hegelianismo de esquerda. Nesse sentido, vale considerar a assertiva no que compreende a universidade e sua relação com a sociedade, no que consideramos extensão universitária.

O laboratório Gilberto Freyre, vem fazendo esforços homéricos para articular uma imbricação entre teoria e prática, mais precisamente, aproximar a universidade da comunidade, bem como a comunidade da universidade. Pois bem, esta relação entre universidade e comunidade é, ou parece seruma via de mão única, em que a universidade se aproxima verticalmente da comunidade e, em alguns casos, depositam seus produtos, a saber, "conhecimento/informação". Tais produtos, no seu conjunto, são pensados como prestação de serviço, mais especificamente, "remédios" para a comunidade, ou seja, uma distorção do que se compreende por extensão universitária no seu sentido pleno.

Esta visão de universidade é herdeira do positivismo comtiano, em que, para esse autor, o papel da ciência é, justamente, ofertar, semelhante a medicina, receita de melhoramento parao corpo social, em que, do olimpo, a ciência, aqui traduzida como universidade, promulga o que é melhor para o corpo social, sem qualquer escuta ou participação da comunidade. Uma vez que a comunidade, ainda segundo a visão comtiana, encontra-se num estado de atraso e sem qualquer possibilidade de participação, com os homens de ciência, da produção do saber.

Pensando nessa relação vertical, oriunda do pensamento comtiano, o laboratório Gilberto Freyre, ao iniciar suas ações junto à comunidade, compreendeu que não 
basta levar a universidade a comunidade, mas que também deve trazer a comunidade para a universidade, para, que a partir dessa via de mão dupla, universidade e comunidade, o conhecimento possa ser compartilhado e partilhado. Desse modo, o laboratório desenvolveu e desenvolve alguns projetos dos quais se destacam: Capoeira: cidadania e cultura, Cidadania e Trabalho, Contação de História, Universidade Popular e Pré-universitário.

Acreditamos que esses projetos possuem potencial para estabelecer aproximação entre a universidade e comunidade, mas a experiência no projeto nos mostrou que precisamos ouvir a comunidade para definirmos como isso pode ser possível.Pois tomando para análise o projeto que se denomina de Capoeira: cidadania e cultura, erradamente, partiraminicialmente da tese deressocializar pela capoeira, sem partir de escuta a comunidade com a qual pretendíamos trabalhar, pois acreditamos que por essa via, capoeira, seria possível atingir os adolescentes e jovens que cumpriam e cumprem medidas socioeducativas. A crença partiu de um conjunto de aprendizados, ações, signos e significados que envolvem o universo da capoeira. Desse modo, o projeto foi apresentado à secretaria municipal de assistência social para sua execução no Centro de Referência Especializado de Assistência social - CREAS do município de União da Vitória.

Decerto que a atividade foi bem aceita por parte da secretaria de assistência social, agentes do CREAS e também pelo ministério público, exceto pelos adolescentes e jovens que cumprem medidas socioeducativas, pois, a extensão universitária, aqui apresentada como capoeira, para os mesmos era uma espécie de punição/castigo, já que, a partir do delito/crime cometido pelo adolescente/jovem, o mesmo deve cumprir uma determinada carga horária de medidas socioeducativas no CREAS de União da Vitória.

Todavia, para os setores sociais; secretaria social, agentes do CREAS e ministério público, a extensão universitária, apresentada pelo laboratório Gilberto Freyre, configurava-se como remédio, pois essa atividade de capoeira, embalada pelas atividades de musicalidade, instrumentação e rodas de dança e jogo poderia criar expectativa de socialização, sobretudo, porque nocorpo do projeto teórico apresentado aos setores sociais, constava leitura de um conjunto teórico que tratava do assunto - ressocialização. Nesse bojo de entendimento, o projeto atingiria completamenteos adolescentes/ jovens infratores de União da Vitória.

Pois bem, a experiência foi desencantadora para os bolsistas universitários, primeiro porque são alunos da licenciatura e, como tal reproduzem, no que compreende a extensão,na lógica vertical da universidade, a partir de seu conhecimento teórico, em que se colocam como homens da ciência transformando o mundo, nesse caso específico, ressocializando adolescentes e jovens: infratores e criminosos. Assim, taldesencanto originou-se do primeiro contato com os adolescentes e jovens, quando os bolsistas acadêmicos não foram bem recebidos pelos adolescentes/jovens que cumprem medidas sócio educativas, pois como citado anteriormente, viram sua participação 
no projeto como uma punição e não como possibilidade de ressocialização, pois não houve uma conversa prévia com os sujeitos do projeto sobre o que implicaria sua participação no projeto, apenas uma determinação judicial de que deveriam se fazer presentes. Entretanto, vale destacar que tiveram uma boa acolhida pelos funcionários do CREAS, pois estesentenderam ser importante o apoio da Universidade.

No entanto, os bolsistas não se intimidaram com a falta de receptividade dos adolescentes/jovens, pelo contrário, apelaram para o uso da autoridade, reivindicaram o lugar hierárquico das relações e demarcaram os poderes entre os acadêmicos e os infratores.É importante destacar que, segundo os bolsistas, os adolescentes e jovens se curvaram a autoridade reivindicada no exercício da ação extensionista. Também, caso não ocorresse disciplina por parte dos adolescentes/jovens, os nomes dos infratores das atividades iriam para um instrumento de controle que se denomina de ficha pessoal que, de algum modo, chegaria ao ministério público/judiciário e, certamente, ocasionariam outras consequências.

Assim, na primeira avaliação dos bolsistas, vitória para os mesmos, pois, os adolescentes e jovens cumpriam com as atividades, ou seja, embrenhavam-se nos instrumentos, cantavam e faziam leituras solicitadas, mesmo sendo a contragosto, o que a nosso ver ilustra que os adolescentes/jovens consideravam o projeto punitivo e não educativo, pois não realizavam as atividades por interesse, mas por imposição.

Com tempo, após longas semanas, os corpos dos adolescentes e jovens, numa interpretação foucaultiana, docilizaram-se, renderam-se a disciplina, bem como a vigilância e, somente nos vagos momentos de intervalo, adolescentes e jovens, emudecidos pela disciplina hierarquizante, entoavam, ainda que de forma tímida, a desesperança e a tragédia de uma vida nua, ou seja, relatavam o seu mundo, o mundo real em que vivem para seus colegas. Essa ação, relato de uma vida que em nada se encaixava nas conversas do projeto ali desenvolvido, fez com que os bolsistas não só repensassem o projeto de capoeira, mas também que estabelecessem escuta e que para além disso fizessem com que a universidade estivesse, de forma efetiva, envolvida com a vida desses atores.

Desse modo, o projeto de capoeira: cultura e cidadania foi reessignificado. Adolescentes e jovens, com novas abordagens, reescreveram as letras musicais dos lamentos $^{1}$ da capoeira com suas histórias, emprestaram seu drama cotidiano para a musicalidade da capoeira. O detalhe observado é que, tomando de assalto Bourdieu, os capitais ali cantados, sequer aproximavam-se da universidade, da vida acadêmica, da produção de saber, o capital, assim podendo chamar, era o retrato de habituscircunscrito no entorno da violência, da violação dos direitos humanos e na marginalização dos mais pobres.

Dessa forma, escutar os lamentos de cada um, por meio da musicalidade, impactados pelo horror do cotidiano, possibilitouao laboratório Gilberto Freyre ampliar o 
projeto "Capoeira: cidadania e cultura", para o que hoje se denomina de "Cidadania e trabalho". As histórias de vida, cantadas, representam vidas vulneráveis ao crime, a prostituição e a marginalidade. Portanto o projeto "cidadania e trabalho" nasceu da escuta de um lamento dos adolescentes/jovens de que: "não há expectativa, não há sonho, não há lugar pra gente". A fala, empalmada pela música, denunciava o rótulo de marginal - quer dizer, "não há como empregar bandido".

Já discutimos a questão de a universidade ser um lugar de privilégio, promotora da ciência, a casa do saber. E também que há um fosso entre ela, a universidade e a comunidade, sobretudo, quando a discussão é centrada na extensão universitária. Mas esta distância, às vezes se rompe pela ousadia e pela inquietação dos envolvidos em projetos dessa natureza, que são de algum modo, confrontados e provocados pela dureza da realidade cotidiana. Mas isso só é possível quando há espaço para escuta a comunidade envolvida. Aqui no caso específico, os bolsistas acadêmicos do projeto Capoeira, intrigados com a realidade em que se encontravam, consultaram, em nome do laboratório Gilberto Freyre, o mercado de trabalho local sobre a possibilidade de parceria entre a universidade e o comércio para estreitar as relações entre os jovens e o caminho do trabalho. Tal ação não trouxe resultados práticos imediatos, pois não há como negar, segundo os bolsistas, que alguns comerciantes receberam bem a ideia, pois, naquele primeiro momento, era como se a universidade estivesse preocupada em formar e qualificar a mão-de-obra. Todavia, de posse da compreensão inteira do projeto, ou seja, de onde vinham e quem era essa mão-de-obra, houve, de forma categórica, uma repulsa instantânea ao projeto, uma vez que a sinalização era para contratação de marginais.

Devemos destacar o esforço dos bolsistas acadêmicos, pois, mesmo com a rotulação do criminoso, por parte do setor empresarial, os bolsistas não se deram por vencido e provocaram outros setores da sociedade, a saber, ministério público e a vara da infância e juventude para que juntos pudessem sensibilizar o empresariado local e assegurar aos adolescentes e jovens a oportunidade do primeiro emprego.

E assim, desse projeto, nasceu outro que se encontra, também, em fase inicial: pesquisar no banco de dados do fórumde uma cidade do interior do estado do Paraná, no Brasil quantos foram os adolescentes e jovens encaminhados para o CREAS e quantos reincidiram no delito/crime. De posse desse número, a pesquisa analisará os programas que são executados com os adolescentes/jovens e quais conseguem estabelecer relações entre a teoria com a prática cotidiana desses adolescentes/jovens a partir de escuta com os mesmos.

Portanto, observamos que a extensão, aqui pensada, tem vínculo efetivo com a comunidade, pois começou com o projeto de "Capoeira: cidadania e cultura" e agregou outro projeto denominado de "Cidadania e trabalho" e, assim, alicerçou a extensão com a pesquisa na medida em que fará pesquisa documental e de campo sobre a efetividade dos projetos que são orquestrados no interior do CREAS. 
O que podemos aferir, no caso específico desse projeto de ressocialização, é como a extensão foi se construindo, quer dizer, partiu de um vício histórico das universidades, mas, ao meio do caminho, aprendeu a duras penas que para ser efetivo, produtivo e transformador deve, antes de tudo, ouvir a comunidade, participar da vida ativa da comunidade e, por meio dessa interação, construir, universidade/comunidade, comunidade/universidade, conhecimento e transformação da realidade.

Ainda em relação a análise dos sessenta três projetos e programas cadastrados na divisão de pesquisa de uma universidade pública brasileira que corresponde a trinta e três proponentes, realizamos busca no currículo dos proponentes cadastrados na plataforma lattesverificando se o programa ou projeto está registrado nessa plataforma, a titulação do proponente e se ocorreu difusão de resultados desses projetos por meio de publicações.

E ao analisarmos as produções dos proponentes, verificamos a hipótese inicial de que na grande maioria dos casos a pesquisa está desvinculada da extensão. Dos trinta e sete proponentes, vinte e cinco são doutores e apenas doze não. Destacamos que ao analisarmos os currículos observamos outros projetos de extensão cadastrados no currículo lattes, porém tomamos como elemento de análise apenas os cadastrados na divisão de extensão da instituição a que o proponente está vinculado, sendo que, verificamos que destes apenas vinte e dois estão cadastrados no lattes, ou seja, quase dois terços dos projetos cadastrados na divisão de extensão não estão cadastrados no currículo dos extensionistas.

Dos trinta e sete proponentes apenas oito tem publicações referentes aos projetos e programas de extensão analisados, sendo que destes, apenas um tem publicação em periódico e quatro em eventos nacionais ou internacionais, as demais produções são todas em seminários internos de extensão.

\section{Conclusões}

Não pretendemos com este trabalho de pesquisa criticar a universidade e seu modo de fazer extensão, mas, para, além disso, buscamos refletir sobre o lugar da extensão no discurso ideológico da indissociabilidade entre ensino, pesquisa e extensão. Para tanto, partimos de estudo e análise de autores e obras que tratam do tema, bem como da experiência extensionista do laboratório Gilberto Freyre e análise dos projetos de extensão e produções dos professores de uma universidade pública brasileira. Pois bem, a partir desse estudo apresentado, concluímos que esta relação interrompida, universidade e sociedade pode ser, à luz da extensão acadêmica, reestabelecida no que compreende a produção do saber e a transformação da realidade. Todavia, para que seja uma relação relevante socialmente e acessível para utilização na fluência entre universidade/comunidade e comunidade/universidade, faz-se premente considerar o lugar de poder em que se encontra a universidade e sua relação vertical para com as 
comunidades, pois, do contrário, com a manutenção dessa visão dominante, onde a universidade, a casa da ciência, arbitra, do ponto de vista da extensão, o que é melhor para a sociedade, sem qualquer escuta e participação das comunidades, o diálogo será interrompido e o papel da extensão reduzido a uma via de mão única.

Por outro lado, para além dessa perspectiva comtiana de universidade, que é pensada como portadora das verdades e transformadora das realidades sociais, aqui já por nós apresentada e criticada, sobretudo, na forma de dialogar com a sociedade por meio da extensão, a universidade não efetiva, em termos práticos, a indissociabilidade entre ensino, pesquisa e extensão, haja vista que, na prática, temos uma dissociabilidade, especialmente, no que compreende a extensão. Esta dissociabilidade foi por nós apresentada, sobretudo, observando a produção acadêmica de pesquisadores com projeto de extensão cadastrado e suas publicações científicas. Todavia, aqui cabe uma última consideração, qual é o lugar da extensão no interior das universidades?

Pensando a partir da experiência que analisamos do laboratório Gilberto Freyre, existe um lugar que deve ser ocupado pela extensão, a saber, a comunidade. E quando se pensa nesse lugar não se trata de reproduzir a lógica da verticalização entre universidade e comunidade, mas para, além disso, trata-se de observar como a prática extensionista contribui para formação humana dos pesquisadores que, a partir dessa inserção nas comunidades, possibilita não só uma vivência com o cotidiano das comunidades, mas oportuniza novos olhares no sentido da formação humana de professores e pesquisadores. Também, pode se considerar como que, a partir dessa prática extensionista, observada no laboratório, a universidade contribui e avança nos projetos, sobretudo, quando é capaz de escutar e dialogar com a comunidade, noutros termos, praticar o que se denomina de via de mão dupla, onde universidade/ comunidade e comunidade/universidade possam construir caminhos de saberes e de transformação da vida cotidiana.

\section{Notes}

1 A musicalidade da capoeira se divide entre as ladainhas, os corridos, as quadras e as chulas, nas quais se destacam o lamento, o sofrimento do negro escravizado, que passa a ser cantado em forma de lamentação.

\section{Referências:}

Bourdieu, P. (2012). O poder simbólico. Rio de Janeiro: Bertrand Brasil.

Comte, A. (1978). Curso de Filosofia Positiva. São Paulo: Nova Cultural.

Foucault, M. (2008). Vigiar e punir: nascimento da prisão. (35ª ed). Petrópolis: Vozes.

Marx, K. (1973). Teses contra Feuerbach. São Paulo: Nova Cultural.

Naidorf, J. e Perrota, D. (2015). La ciencia social politizada y móvil de una nueva agenda latinoamericana orientada a prioridades. Revista de la Educación Superior, 174 (XLIV), 19-46. 
Perini, G.B.\&Bufrem, L.S. (2008). Por uma educação além do ensino. In T. M. F. B. Garcia, L. S. Bufrem\&T. M. Baibich-Faria (Org.). Saberes e prática no ensino superior (pp. 21-40). ljuí: Editora Unijuí.

Santos, M. (2016). Entrevista Explosiva com Milton Santos. Revista Caros Amigos. 17 ed. [Disponível em: http://www.carosamigos.com.br/index.php/grandes-entrevistas/6047-entrevista-explosiva-commilton-santos. Acesso em: 12/02/2017].

Vieira Pinto, Á. (1994). A questão da universidade. (2ª ed). São Paulo: Cortez.

Maria Ivete Basniak

Graduação em Matemática pela Faculdade Estadual de Filosofia, Ciências e Letras de União da Vitória, Mestrado em Métodos Numéricos em Engenharia e Doutorado em Educação pela Universidade Federal do Paraná (2014). É professora adjunta da Universidade Estadual do Paraná, Campus de União da Vitória.

Email: basniak2000@yahoo.com.br ORCID: 0000-0001-5172-981X

\section{Antônio Charles Santiago Almeida}

Graduado em Filosofia pela Universidade Estadual de Santa Cruz UESC (2004). Mestre em Ciências Sociais pela Pontifícia Universidade Católica de São Paulo PUC - SP (2009) e Doutor em Educação pela Universidade

Federal do Paraná - UFPR (2015). É professor adjunto da Universidade Estadual do Paraná - UNESPAR/FAFIUV. Email: sandiabo@yahoo.com.br

Sani de Carvalho Rutz da Silva Licenciatura em Matemática pela Universidade Estadual de Ponta Grossa (1993), Mestrado em Matemática Aplicada e doutorado em Ciência dos Materiais pela Universidade Federal do Rio Grande do Sul (2003). Atualmente é professor da Universidade Tecnológica Federal do Paraná.

Email: sani@utfpr.edu.br ORCID: 0000-0002-1548-5739

Correspondência Maria Ivete Basniak Departamento de Ciências Exatas e Biológicas

Campus de União da Vitória Universidade Estadual do Paraná Rua Pernambuco, 858 87701-010 - Centro Paranavaí, Paraná (Brasil)

Data de submissão: Dezembro 2016

Data de avaliação: Janeiro 2017 Data de publicação: Março de 2018 